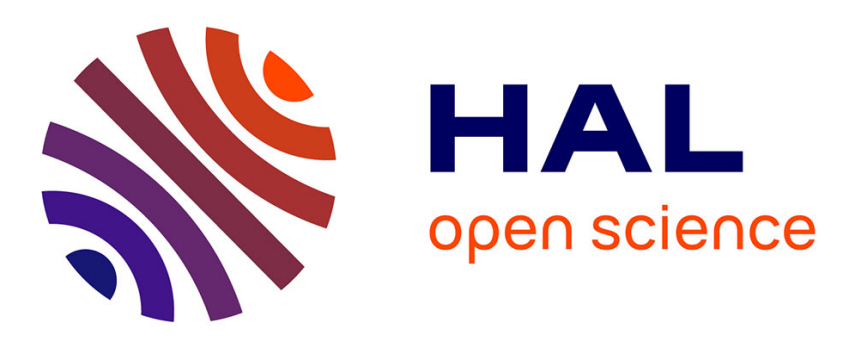

\title{
Added value of one-view breast tomosynthesis combined with digital mammography according to reader experience
}

Isabelle Thomassin-Naggara, Nicolas Perrot, Sophie Dechoux, Carine Ribeiro, Jocelyne Chopier, Cedric de Bazelaire

\section{To cite this version:}

Isabelle Thomassin-Naggara, Nicolas Perrot, Sophie Dechoux, Carine Ribeiro, Jocelyne Chopier, et al.. Added value of one-view breast tomosynthesis combined with digital mammography according to reader experience. European Journal of Radiology, 2014, 84 (2), pp.235-241. 10.1016/j.ejrad.2014.10.022 . hal-01087639

\section{HAL Id: hal-01087639 \\ https: / hal.sorbonne-universite.fr/hal-01087639}

Submitted on 26 Nov 2014

HAL is a multi-disciplinary open access archive for the deposit and dissemination of scientific research documents, whether they are published or not. The documents may come from teaching and research institutions in France or abroad, or from public or private research centers.
L'archive ouverte pluridisciplinaire HAL, est destinée au dépôt et à la diffusion de documents scientifiques de niveau recherche, publiés ou non, émanant des établissements d'enseignement et de recherche français ou étrangers, des laboratoires publics ou privés. 
Added value of one-view breast tomosynthesis combined with digital mammography according to reader experience

Isabelle Thomassin-Naggara ${ }^{1,2,3}$, Nicolas Perrot ${ }^{3,4}$,Sophie Dechoux ${ }^{1,3}$, Carine Ribeiro ${ }^{4}$, Jocelyne Chopier ${ }^{3}$, Cedric de Bazelaire ${ }^{5}$

1-Sorbonne Universités, UPMC Univ Paris 06, IUC, 75005, Paris, France

2-INSERM, UMR970, Equipe 2, Imagerie de l'angiogenèse, 75005, Paris, France

3-AP-HP, Hôpital Tenon, department of radiology 4 rue de la Chine, 75020, Paris, France

4- Centre Pyramides, Paris, France

5-APHP, department of radiology, Hôpital Saint Louis, 75010, Paris, France

Type of manuscript: Original research

Running title: Breast tomosynthesis

\section{Correspondence:}

Isabelle Thomassin-Naggara,

Service de Radiologie,

Hôpital Tenon, 4 rue de la Chine,

75020, Paris, France.

Tel.: +33156017830

Fax: +33156016402

E-mail: isabelle.thomassin@tnn.aphp.fr 
Added value of one-view breast tomosynthesis combined with digital mammography according to reader experience

Highlights for review

Breast tomosynthesis improves diagnostic performance especially for radiologists with lower experience in mammography

Adding only one-view digital breast tomosynthesis to mammography improves the cancer detection rate

Breast tomosynthesis is mainly useful for helping radiologists to detect architectural distortion 


\begin{abstract}
Purpose: To retrospectively evaluate the added value of one-view breast tomosynthesis in adjunct with mammography to characterize breast lesions.

Materials and methods: Our institutional ethics committees approved the study and granted a waiver of informed consent. One hundred fifty-five women (mean age, 51.3 years, range: 24-92 years) who systematically underwent mammography and breast tomosynthesis with subsequent percutaneous biopsy were analyzed. Four radiologists (two seniors, R1 and R2, and two juniors, R3 and R4 with 30, 10, 3 and 1 years of experience in breast imaging, respectively) independently reviewed exams in 2 steps: mammography alone and tomosynthesis in adjunct with mammography. The lesions in the cohort included $39.3 \%$ $(61 / 155)$ cancers, $2.5 \%(4 / 155)$ high-risk lesions and 58.1\% (90/155) benign lesions. A receiver operating characteristic (ROC) curve analysis was performed to compare the results of the two readings.
\end{abstract}

Results: There was almost perfect agreement irrespective of reader experience for the reading of the mammography in adjunct with tomosynthesis, whereas agreement was poor between junior and senior readers for the reading of mammography alone. Area under the ROC (Az) values for the tomosynthesis in adjunct with mammography were significantly better than $\mathrm{Az}$ values for mammography alone for all readers except the most experienced, for whom only a tendency was noted. The proportion of cancers undiagnosed by mammography alone that were well diagnosed by tomosynthesis in adjunct with mammography was $6.5 \%(4 / 61)$, $13.1 \%(8 / 61), 27.8 \%(17 / 61)$ and $26.2 \%(16 / 61)$ for Readers $1,2,3$ and 4 , respectively. The proportion of false positive cases induced by the addition of breast tomosynthesis to mammography was $2.1 \%(2 / 94), 2.1 \%(2 / 94), 9.5 \%$ (9/94) and $12.7 \%(12 / 94)$ for Readers 1 , 2,3 and 4 , respectively. 
Conclusion: Adding breast tomosynthesis to mammography improved sensitivity and negative predictive value for all readers except for the most experienced one, in whom only a tendency for improvement was noted.

Keywords: Breast tomosynthesis $\bullet$ Mammography $\bullet$ cancer $\bullet$ diagnosis 


\section{Introduction}

Mammography is the first-line technique for diagnostic imaging of breast pathology. While this technique is highly sensitive (80-90\%) for less dense breasts (types 1 and 2), its sensitivity is only $50-60 \%$ for dense breasts (types 3 and 4) [1]. This phenomenon is due to the superimposition of breast tissue, because mammography is a $2 \mathrm{D}$ projection technique and, similarly to "anatomical noise", normal gland limits the visibility of breast abnormalities. Another factor influencing cancer visibility is the tumor pattern, such as lobular cancer, which in some patients may not produce any mass and may be difficult to detect on 2D imaging [2].

Recently, with the development of digital mammography, a new technique named breast tomosynthesis has been developed, offering 3D mammographic acquisition. This technique is derived from tomography and consists in a series of exposures made on the same film while the tube moves in definite angulations. This imaging technique allows visualization of the breast in three dimensions and lowers the impact of tissue overlap. Thus, theory suggests that this technique could be useful in a routine setting by potentially increasing both the sensitivity and specificity for the detection and characterization of breast lesions. As tomosynthesis is a new technique, the majority of initial studies published on the technique deal with optimizing the physical and geometric parameters for tomosynthesis, [3, 4] improving the reconstruction algorithms, [5, 6] and developing CAD for tomosynthesis [710]. In addition, most of these studies were performed on a small number of patients.

Recently, breast tomosynthesis was proven to be better than mammography [11], including for use in a population-based screening program $[12,13]$, and it could possibly be implemented in our screening program in the future. However, one of the primary uses of digital breast tomosynthesis is likely to be in diagnosis, to optimize lesion characterization and improve positive predictive values of percutaneous biopsies, which, in a large majority of 
cases, reveal benign entities. Few papers have proposed any guidelines on how to use this technique in daily practice [14].

The aim of our study was therefore to report our experience in a clinical routine use of tomosynthesis, with an evaluation of the added value of this technique by comparing the diagnostic accuracy of breast tomosynthesis combined with mammography with the accuracy of mammography alone. Our purpose was not to compare the accuracy of the two techniques but to evaluate if tomosynthesis in adjunct with mammography is better than mammography alone 


\section{Materials and methods}

Our institutional ethics committee (Comité de Protection des Personnes Ile de France V) approved the study and granted a waiver of informed consent.

\section{$\underline{\text { Population }}$}

Between December 12009 and July 31 2011, all women who underwent mammography with subsequent percutaneous biopsy in our center were consecutively included $(n=202)$. We excluded patients with only craniocaudal breast tomosynthesis $(n=14)$, patients lost to follow-up $(n=7)$, patients with breast implants $(n=9)$ and patients lost to our picture archiving and communication system (PACS) $(n=17)$.

The final cohort consisted in 155 women (mean age, 51.3 years, range: 24-92 years). Seventy-one patients (45.8\%) were menopausal and 84 (54.1\%) were non menopausal in. Familial history of breast cancer was found in $36.1 \%(56 / 155)$ and a personal history of breast cancer in 9\% (14/155). Indications for mammography were screening $(n=118), 6$ months' follow up of BI-RADS 3 lesion $(n=2)$, systematic follow-up after breast cancer $(n=13)$ and clinical abnormality $(n=21)$ including palpable lump $(n=19)$, nipple discharge $(n=1)$ and nipple retraction $(\mathrm{n}=1)$.

\section{$\underline{\text { Acquisition }}$}

Mammography was performed on a digital breast mammography system (Selenia Dimensions 3D System, Hologic (Bedford, Massachussetts, USA)). All women underwent digital mammography in two views (craniocaudal $[\mathrm{CC}]$ and mediolateral [MLO]) of both breasts, systematically followed by bilateral tomosynthesis in one view (MLO). The acquisition protocol was set to 11 projection images over a $15^{\circ}$ arc from $-7.5^{\circ}$ to $+7.5^{\circ}$ on a breast compressed in exactly the same MLO position as the mammographic acquisition. The image receptor was a 70-micron pixel pitch selenium direct-capture detector. 


\section{$\underline{\text { Data analysis }}$}

Four radiologists (two seniors: R1 and R2; two juniors: R3 and R4), with respectively 30 years, 10 years, 3 years and 1 year of experience in breast imaging, independently reviewed exams in 2 steps. The readers were blinded to the pathological results but were not blinded to clinical examination or to prior mammography when available as routine practice.

In a first step, readers only analyzed mammographic acquisition including oblique and craniocaudal views: breast density was subjectively assessed from a global evaluation of parenchymal density and was categorized as per the American College of Radiology's BIRADS lexicon for breast density descriptors, from fatty replaced (grade A), to extremely dense (grade D). The most suspicious mammographic abnormality was characterized as mass, asymmetric density, cluster of microcalcifications and architectural distortion. Lesion size was recorded using the two mammographic views. Finally, readers classified the abnormality

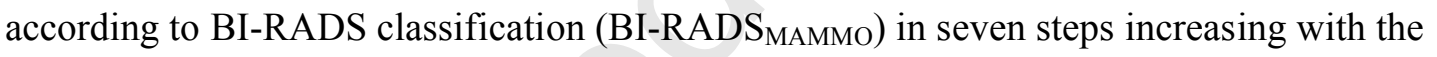
probability of malignancy, according to the American College of Radiologists: $1=$ BI-RADS 1 (negative), 2 = BI-RADS 2 (benign finding), 3 = BI-RADS 3 (probably benign finding), 4 $=\mathrm{BI}-\mathrm{RADS} 4 \mathrm{~A}$ (low suspicious abnormality), $5=$ BI-RADS 4B (medium suspicious abnormality), $6=$ BI-RADS 4C (highly suspicious abnormality) and $7=$ BI-RADS 5 (highly suggestive of malignancy). Only the most suspicious finding was considered per patient.

In a second step, immediately after the first step, readers analyzed breast tomosynthesis. The abnormality was characterized as mass, asymmetric density, cluster of microcalcifications and architectural distortion. Lesion size was recorded using breast tomosynthesis acquisition on the slice judged as the best for the measurement by each reader. Finally, readers included tomosynthesis information to obtain a new BI-RADS classification, named "BI-RADS мАммO+томо". 
At the end of the procedure, the side and the location of the abnormality subsequently biopsied were given to each reader. If the lesion described did not correspond to the location of the biopsy, the score of the lesion was re rated as BI-RADS 1 and the lesion was considered as missed either by mammography alone or by both mammography and tomosynthesis.

\section{$\underline{\text { Reference standard }}$}

Histopathological findings included 90 benign lesions, 4 high-risk lesions and 61 malignant tumors (Table 1). The diagnoses were established by surgical pathology $(n=74)$, or percutaneous biopsy followed by a 1 -year negative follow-up $(n=81)$. All malignant tumors and high-risk lesions were confirmed by surgical excision. Among patients with benign lesions, 9 underwent surgery (8 radial scar and one papilloma).

\section{$\underline{\text { Statistical analysis }}$}

Descriptive analysis was performed using a nonparametric Mann-Whitney test for continuous variables and Fisher's exact test for categorical or nominal variables.

Confidence level ratings of the images were also used to calculate the sensitivity, specificity and accuracy for each image data set in the diagnosis of malignancy. Ratings of BI-RADS 1, 2 or 3 indicated a reading of a benign lesion. Ratings of 4 and 5 indicated a reading of a malignant lesion. The accuracy of mammography and of mammography and tomosynthesis combined was compared using McNemar's two-tailed test. The following hypotheses were tested: (a) same number of lesions correctly classified by both image data sets; (b) different number of lesions correctly classified by both image data sets.

Quadratic $\kappa$ coefficients were calculated to assess interobserver agreement between the two junior and two experienced breast imaging radiologists for lesion characterization, using 
the following scale: $0.00-0.20$ indicating slight agreement; $0.21-0.40$, fair agreement; $0.41-$ 0.60, moderate agreement; $0.61-0.80$, substantial agreement; and 0.81-1.00, almost perfect agreement).

A receiver operating characteristic (ROC) curve analysis was performed to compare the results of readings of mammography and of tomosynthesis for each reader in adjunct with mammography ( $\underline{\text { www.medcalc.be)}}$. Overall ROC curves (BIRADS scores) averaged over four readers for mammography and tomosynthesis in adjunct with mammography were also compared using Metz-ROC software (http://metz-roc.uchicago.edu/).

A $P$ value of less than 0.05 was considered to indicate a statistically significant difference. Statistical analyses were performed using MedCalc software (www.medcalc.be, Belgium). 


\section{Results}

Descriptive results

Breast density was rated by the four readers as A from 5/155 to $9 / 155$ (3.2\% to $5.8 \%)$, as B from $42 / 155$ to $45 / 155$ (27\% to $29 \%$ ), as C from $74 / 155$ to $84 / 155(47.7 \%$ to $54.1 \%$ ) and D from $21 / 155$ to $30 / 155(13.5 \%$ to $19.3 \%)$ of the population studied. Whatever the reader considered, breast density was rated C or D in more than $50 \%$ of the patients studied.

Using mammography alone, an abnormality was detected in 118/155 (76.1\%), $121 / 155(78 \%), 81 / 155(52.2 \%)$ and $71 / 155(45.8 \%)$ women, for readers $1,2,3$ and 4 , respectively. These lesions were characterized as an asymmetric density $\left(\mathrm{nR}_{1}=12, \mathrm{nR}_{2}=14\right.$, $\left.\mathrm{nR}_{3}=3, \mathrm{nR}_{3}=8\right)$, as a mass $\left(\mathrm{nR}_{1}=33, \mathrm{nR}_{2}=31, \mathrm{nR}_{3}=25, \mathrm{nR}_{4}=30\right)$, as a distortion $\left(\mathrm{nR}_{1}=38\right.$, $\left.\mathrm{nR}_{2}=42, \mathrm{nR}_{3}=17, \mathrm{nR}_{4}=18\right)$ or as a cluster of microcalcifications $\left(\mathrm{nR}_{1}=35, \mathrm{nR}_{2}=34, \mathrm{nR}_{3}=36\right.$, $\mathrm{nR}_{4}=35$ ) (figure 1).

When tomosynthesis was added, an abnormality was detected in 124/155 (80\%), 130/155 (83.8\%), 106/155 (68.3\%) and 99/155 (63.8\%) for readers 1, 2, 3 and 4, respectively. Thus, mammography classified as negative (BIRADS 1 or 2) was reclassified as positive (BIRADS $3,4,5)$ in $6 / 37(16.2 \%)$ including 5 distortions and one mass, $9 / 34$ including 8 distortions and one mass (26.4\%), 27/74 including 22 distortions, 4 masses, and one cluster of microcalcifications (36.4\%) and 28/64 including 23 distortions and 5 masses (43.7\%), for readers $1,2,3$ and 4, respectively (figure 2 and 3).

Comparative performance of mammography and the combination of mammography and tomosynthesis according to reader experience

Interobserver agreement 
Using mammography alone, there were an almost perfect agreement for lesion characterization between the two junior readers (R3 and R4) and between the two senior readers (R1 and R2) but there was a poor agreement between junior and senior readers.

When breast tomosynthesis was added, these differences disappeared, with an almost perfect agreement whatever the combination performed (between junior readers, between senior readers or between senior and junior readers) (Kappa values from 0.731 to 0.880 ) (Table 2).

ROC analysis

Calculated by averaging the curves from the 4 readers, the mean area under the ROC for BIRADS $\operatorname{BIRADS}_{\text {MAMMO }}(\mathrm{Az}=0,685)(\mathrm{p}<0,01)$.

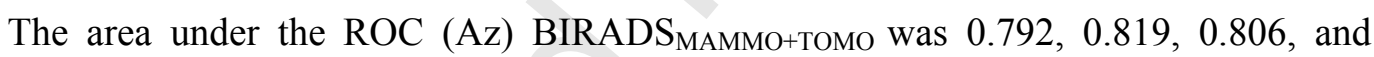

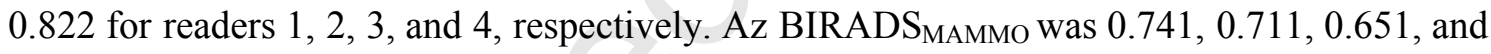
0.665 for readers $1,2,3$, and 4 , respectively. There was a significant difference between

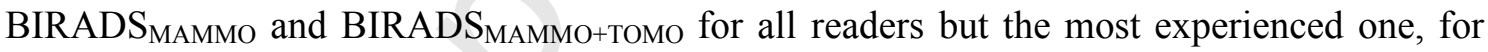
whom there was only a tendency for BIRADS MAMMO + TOMO to be superior to BIRADS $_{\text {MAMMO }}$ (Table 3). (Figure 4)

Comparison of the accuracy of mammography with and without tomosynthesis (Table 4)

Whatever the experience of the reader considered, the addition of breast tomosynthesis improved the sensitivity and negative predictive value of mammography read alone.

The accuracy of the tomosynthesis in adjunct with mammography was higher than that of mammography alone for reader $2(P=0.02)$ and reader $3(P=0.03)$. For reader 4 , the accuracy of the combination of mammography and tomosynthesis was higher than that of 
mammography alone only in the malignant lesion subgroup $(P<0.0001)$ due to the high rate of false positives for this junior reader (12/94). For reader 1, no difference was found between mammography alone and mammography with tomosynthesis. The addition of tomosynthesis increased correctly the diagnostic confidence (i.e. the level of confidence increased in truepositive cases and decreased in true-negative cases) in 3.87\% (6/155), $7 \%(11 / 155), 10.4 \%$ $(13 / 155)$ and $3.87 \%(6 / 155)$ cases for readers $1,2,3$ and 4 , respectively (Table 5).

The proportion of cancers undiagnosed by mammography alone that were well diagnosed by the addition of breast tomosynthesis was $6.5 \%(4 / 61), 13.1 \%(8 / 61), 27.8 \%$ $(17 / 61)$ and 26.2\% (16/61) for readers 1, 2, 3 and 4, respectively. These lesions corresponded to architectural distortion in $100 \%(4 / 4), 100 \%(8 / 8), 88 \%(15 / 17)$ and $75 \%(12 / 16)$ of cases for readers 1, 2, 3 and 4, respectively. All these lesions were invasive cancers whatever the reader considered and were invasive lobular carcinoma in 3/4 (75\%), 4/8 (50\%), 4/17 (23.5\%) and 4/16 (25\%) of cases for readers $1,2,3$ and 4, respectively.

The proportion of false-positive cases that were induced by the addition of breast tomosynthesis to mammography was 2/94 (2.1\%), 2/94 (2.1\%), 9/94 (9.5\%) and 12/94 $(12.7 \%)$ for readers $1,2,3$ and 4 , respectively. 


\section{Discussion}

Our study demonstrates that adding one-view digital breast tomosynthesis to mammography improved diagnostic performance and reproducibility, with a decrease of between $6.5 \%$ and $26.2 \%$ in the proportion of cancers that remained undiagnosed. There was

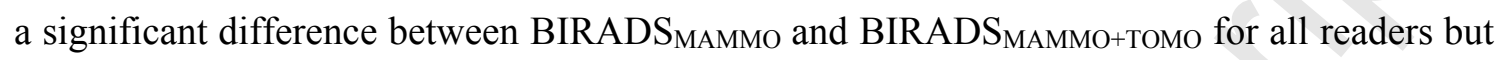
the most experienced one, for whom there was only a tendency for BIRADS $\mathrm{MAMMO}_{\text {+ TOMO }}$ to be superior to BIRADS MAMMO. $_{\text {. }}$

The first pilot studies on breast tomosynthesis showed that this technique allows a better image quality than digital mammography [15], with the potential to decrease the recall rate when used adjunctively with digital mammography by improving specificity [16]. In fact, Gur et al. demonstrated that the added value of breast tomosynthesis was only found when it was added to the reading of 2D mammography $(P>0.0001)$, while no significant difference was found between breast tomosynthesis alone and 2D mammography [17]. However, most of the subsequent papers published between 2008 and 2011 compared breast tomosynthesis alone to mammography alone and showed that tomosynthesis alone did not outperform digital mammography, especially using a one-view tomosynthesis acquisition $[14,18,19]$. One possible explanation is that mammography is slightly more sensitive than breast tomosynthesis to detect calcification [20], while tomosynthesis seems to improve visualization of masses and architectural distortions. [11].

Thus, our study was based on the hypothesis that mammography and breast tomosynthesis complement each other and that their combined use might reduce the error rate for false negatives compared to mammography alone, in line with more recently published findings [21, 22]. Our results confirm that a combined interpretation of mammography and tomosynthesis improve diagnostic accuracy, as previously demonstrated [17, 23]. In the 
retrospective study by Gur et al. on 125 patients, the authors found that tomosynthesis improved both sensitivity and specificity (with a sensitivity of $93 \%$ and a specificity of $72 \%$ for combined reading, compared to a sensitivity of $88 \%$ and a specificity of $60 \%$ for mammography alone) [17]. In comparison with the results of Gur et al., our mammographic and combined mammographic and tomosynthesis sensitivities were relatively low because we considered our BIRADS-3 findings as negative as Rafferty et al., who obtained comparable values [21].

In contrast to the study by Rafferty et al., our work details the specific added value for each reader and reveals that it mainly depends on reader experience. In fact, using ROC curve analysis, we found a significant difference between BIRADS MAMMO $_{\text {and }}$

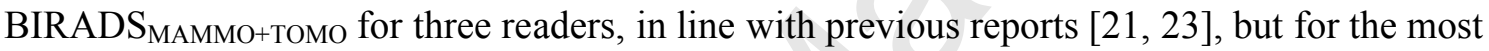
experienced reader there only a tendency for superiority of BIRADS ${ }_{M A M M O}+$ TOMO in

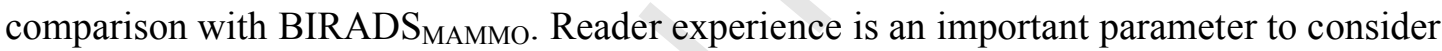
when evaluating the accuracy of the added value of tomosynthesis. Our study emphasizes that the added value of breast tomosynthesis when combined with mammography depends on reader experience. This is in line with Wallis et al., who found that two-view tomosynthesis outperformed 2D mammography, but only for readers with the least experience [19]. Their study differs from ours in that it compared two-view and single-view tomosynthesis alone with digital mammography alone. Moreover, our study demonstrates that tomosynthesis improves reproducibility of the reading, especially between junior and senior readers, and that tomosynthesis makes mammographic interpretation easier for juniors and homogenizes diagnostic performance, with a lower impact of experience on diagnostic accuracy.

Our study confirms that adding tomosynthesis to mammography improves the cancer detection rate, as previously demonstrated in an unblinded study by Anderson et al. [2] and, more recently, in a large population-based screening program $[12,24]$. In our study, the 
addition of tomosynthesis decreased the proportion of cancers that remained undiagnosed by between $6.5 \%$ and $26.2 \%$. Moreover, our study confirms that the tomosynthesis enables the detection of more invasive cancer (12): In our experience, all cancers detected by tomosynthesis when combined with mammography were invasive cancers. Our data demonstrate that the assessment was accurate, even in a population where more than $50 \%$ of the patients were considered, whatever the reader, to have dense breast. This probably explains why our increasing detection rate was lower than that recently reported by Skanne et al. (27\% increase) [12]. Moreover, our inclusion criteria introduced a selection bias with an incompletely blinded reading. However, this potential bias did not appear to have an impact on false-positive rates, which remained lower, whatever the level of reader experience, than the $15 \%$ decrease reported by Per Skanne [12].

In our study, subgroup analysis demonstrates that breast tomosynthesis is mainly useful for helping radiologists to detect architectural distortion (depending on reader experience, $75 \%$ to $100 \%$ of all cancers missed by mammography were well-diagnosed by breast tomosynthesis), as suggested by Skaane et al. [12]. Regarding the type of cancer detected, breast tomosynthesis led to improved detection of invasive lobular cancer compared to mammography, mainly for experienced readers ( $75 \%$ and $50 \%$ of missed cancers) but not for less experienced readers $(23.5 \%$ and $25 \%$ of missed cancers $)$ as described by Teertstra et al. [14].

Our study has several limitations. First, as suggested by Rafferty et al., we performed breast tomosynthesis in a single view to limit the added radiation dose [11]. However, some authors have suggested the superiority of both MLO and CC projections for breast tomosynthesis [14]. In addition, MLO acquisition was chosen, which could be more frequently responsible for inadequate visualization due to more frequent patient motion. Moreover, Andersson et al. reported that cancers were more obvious in the $\mathrm{CC}$ view in the 
majority of cases because of a smaller overlap of fibroglandular tissue than in MLO views [2]. As these authors emphasize, the problem of obscuring tissue is related to the morphology of the lesion and mainly affects the detection of round masses [2]. This is probably why, in our study, all of the cancers missed by mammography were detected using tomosynthesis by an architectural distortion. Thus, our study likely underestimates the added value of tomosynthesis for round masses. Second, due to our inclusion criteria (all women who underwent mammography with subsequent percutaneous biopsy), the interpretation of mammography and breast tomosynthesis could have produced 'distorted' ROC results, because readers would have forced a sort of "lesion searching" process. However, this bias is equivalent for both procedures.

\section{Conclusion}

In conclusion, adding breast tomosynthesis to mammography improves reproducibility and diagnostic performance especially for radiologists with lower experience in mammography. However, for the overall readers, our study demonstrated a substantial decrease of between $6.5 \%$ and $26.2 \%$ in the proportion of cancers that remained undiagnosed, especially by improving the detection of architectural distortion. 


\section{REFERENCES}

1. Leconte I, Feger C, Galant C, Berliere M, Berg BV, D'Hoore W, Maldague B: Mammography and subsequent whole-breast sonography of nonpalpable breast cancers: the importance of radiologic breast density. AJR Am J Roentgenol 2003, 180(6):1675-1679.

2. Andersson I, Ikeda DM, Zackrisson S, Ruschin M, Svahn T, Timberg P, Tingberg A: Breast tomosynthesis and digital mammography: a comparison of breast cancer visibility and BIRADS classification in a population of cancers with subtle mammographic findings. Eur Radiol 2008, 18(12):2817-2825.

3. Zhou J, Zhao B, Zhao W: A computer simulation platform for the optimization of a breast tomosynthesis system. Med Phys 2007, 34(3):1098-1109.

4. Wu T, Moore RH, Rafferty EA, Kopans DB: A comparison of reconstruction algorithms for breast tomosynthesis. Med Phys 2004, 31(9):2636-2647.

5. $\mathrm{Wu} \mathrm{T}$, Moore RH, Kopans DB: Voting strategy for artifact reduction in digital breast tomosynthesis. Med Phys 2006, 33(7):2461-2471.

6. Zhang Y, Chan HP, Sahiner B, Wei J, Goodsitt MM, Hadjiiski LM, Ge J, Zhou C: A comparative study of limited-angle cone-beam reconstruction methods for breast tomosynthesis. Med Phys 2006, 33(10):3781-3795.

7. Reiser I, Nishikawa RM, Giger ML, Wu T, Rafferty EA, Moore R, Kopans DB: Computerized mass detection for digital breast tomosynthesis directly from the projection images. Med Phys 2006, 33(2):482-491.

8. Chan HP, Wei J, Sahiner B, Rafferty EA, Wu T, Roubidoux MA, Moore RH, Kopans DB, Hadjiiski LM, Helvie MA: Computer-aided detection system for breast masses on digital tomosynthesis mammograms: preliminary experience. Radiology 2005, 237(3):1075-1080.

9. Chan HP, Wei J, Zhang Y, Helvie MA, Moore RH, Sahiner B, Hadjiiski L, Kopans DB: Computer-aided detection of masses in digital tomosynthesis mammography: comparison of three approaches. Med Phys 2008, 35(9):4087-4095.

10. Reiser I, Nishikawa RM, Edwards AV, Kopans DB, Schmidt RA, Papaioannou J, Moore RH: Automated detection of microcalcification clusters for digital breast tomosynthesis using projection data only: a preliminary study. Med Phys 2008, 35(4):1486-1493. 
11. Rafferty EA: Digital mammography: novel applications. Radiol Clin North Am 2007, 45(5):831-843, vii.

12. Skaane P, Bandos AI, Gullien R, Eben EB, Ekseth U, Haakenaasen U, Izadi M, Jebsen IN, Jahr G, Krager M et al: Comparison of Digital Mammography Alone and Digital Mammography Plus Tomosynthesis in a Population-based Screening Program. Radiology 2013,Apr; 267(1):47-56.

13. Bernardi D, Ciatto S, Pellegrini M, Anesi V, Burlon S, Cauli E, Depaoli M, Larentis L, Malesani V, Targa L et al: Application of breast tomosynthesis in screening: incremental effect on mammography acquisition and reading time. Br J Radiol 2012, 85(1020):e1174-1178.

14. Teertstra HJ, Loo CE, van den Bosch MA, van Tinteren H, Rutgers EJ, Muller SH, Gilhuijs KG: Breast tomosynthesis in clinical practice: initial results. Eur Radiol 2010, 20(1):16-24.

15. Good WF, Abrams GS, Catullo VJ, Chough DM, Ganott MA, Hakim CM, Gur D: Digital breast tomosynthesis: a pilot observer study. AJR Am J Roentgenol 2008, 190(4):865-869.

16. Poplack SP, Tosteson TD, Kogel CA, Nagy HM: Digital breast tomosynthesis: initial experience in 98 women with abnormal digital screening mammography. AJR Am J Roentgenol 2007, 189(3):616-623.

17. Gur D, Abrams GS, Chough DM, Ganott MA, Hakim CM, Perrin RL, Rathfon GY, Sumkin JH, Zuley ML, Bandos AI: Digital breast tomosynthesis: observer performance study. AJR Am J Roentgenol 2009, 193(2):586-591.

18. Gennaro G, Toledano A, di Maggio C, Baldan E, Bezzon E, La Grassa M, Pescarini L, Polico I, Proietti A, Toffoli A et al: Digital breast tomosynthesis versus digital mammography: a clinical performance study. Eur Radiol 2010, 20(7):1545-1553.

19. Wallis MG, Moa E, Zanca F, Leifland K, Danielsson M: Two-view and single-view tomosynthesis versus full-field digital mammography: high-resolution X-ray imaging observer study. Radiology 2012, 262(3):788-796.

20. Spangler ML, Zuley ML, Sumkin JH, Abrams G, Ganott MA, Hakim C, Perrin R, Chough DM, Shah R, Gur D: Detection and classification of calcifications on digital breast tomosynthesis and 2D digital mammography: a comparison. AJR Am J Roentgenol 2011, 196(2):320-324.

21. Rafferty EA, Park JM, Philpotts LE, Poplack SP, Sumkin JH, Halpern EF, Niklason LT: Assessing radiologist performance using combined digital mammography and 
breast tomosynthesis compared with digital mammography alone: results of a multicenter, multireader trial. Radiology 2013, 266(1):104-113.

22. Zuley ML, Bandos AI, Ganott MA, Sumkin JH, Kelly AE, Catullo VJ, Rathfon GY, Lu AH, Gur D: Digital breast tomosynthesis versus supplemental diagnostic mammographic views for evaluation of noncalcified breast lesions. Radiology 2013, 266(1):89-95.

23. Michell MJ, Iqbal A, Wasan RK, Evans DR, Peacock C, Lawinski CP, Douiri A, Wilson R, Whelehan P: A comparison of the accuracy of film-screen mammography, full-field digital mammography, and digital breast tomosynthesis. Clin Radiol 2012, 67(10):976-981.

24. Ciatto S, Houssami N, Bernardi D, Caumo F, Pellegrini M; Brunelli S, Tuttobene P, Bricolo P, Fanto C, Valentini M, Montemezzi S, Macaskill P. Integration of 3D digital mammography with tomosynthesis for population breast-cancer screening (STORM): a prospective comparison study Lancet Oncol 2013, 14(7):583-9 


\section{TABLES}

Table 1 Pathological diagnosis

\begin{tabular}{|l|l|l|}
\hline & & $\begin{array}{l}\text { Population } \\
(n=155)\end{array}$ \\
\hline $\begin{array}{l}\text { Establishment of final } \\
\text { diagnosis }\end{array}$ & $\begin{array}{l}\text { Surgical pathology } \\
\text { Percutaneous biopsy + short-term follow-up }\end{array}$ & $\begin{array}{l}47.7 \%(74) \\
52.2 \%(81)\end{array}$ \\
\hline Final diagnosis & BENIGN LESIONS & $\mathbf{5 8 . 1 \% ( 9 0 )}$ \\
& Ductal ectasia & $2.6 \%(4)$ \\
& Intramammary lymph node & $1.3 \%(2)$ \\
& Fat necrosis & $0.6 \%(1)$ \\
& Apocrine metaplasia & $4.5 \%(7)$ \\
& Epithelial hyperplasia & $5.2 \%(8)$ \\
& Fibrocystic changes & $18.7 \%(29)$ \\
& Papilloma & $2.6 \%(4)$ \\
& Fibroadenoma & $16.8 \%(26)$ \\
& Radial scar & $5.8 \%(9)$ \\
& HIGH-RISK LESIONS & $\mathbf{2 . 6 \% ( 4 )}$ \\
& Atypical ductal hyperplasia (ADH) & $0.6 \%(1)$ \\
& Lobular carcinoma in situ (LCIS) & $1.3 \%(2)$ \\
& Atypical lobular hyperplasia (ALH) & $0.6 \%(1)$ \\
& MALIGNANT TUMORS & $\mathbf{3 9 . 3 \% ( 6 1 )}$ \\
& Ductal carcinoma in situ (DCIS) & $6.4 \%(10)$ \\
& Invasive ductal carcinoma & $27 \%(42)$ \\
& Invasive lobular carcinoma & $5.8 \%(9)$ \\
& & \\
\hline
\end{tabular}

Table 2 Interobserver agreement

\begin{tabular}{|l|c|c|c|}
\hline & & BIRADS $_{\text {МАMмO }}$ & BIRADS $_{\text {МАMмO+томо }}$ \\
\hline Between senior readers & R1-R2 & $0.814(+/-0.08)$ & $0.874(+/-0.08)$ \\
\hline Between junior readers & R3-R4 & $0.792(+/-0.08)$ & $0.880(+/-0.08)$ \\
\hline \multirow{2}{*}{$\begin{array}{l}\text { Between junior and } \\
\text { senior readers }\end{array}$} & R2-R3 & $0.446(+/-0.07)$ & $0.731(+/-0.07)$ \\
\cline { 2 - 4 } & R1-R3 & $0.482(+/-0,07)$ & $0.746(+/-0.08)$ \\
\cline { 2 - 4 } & R2-R4 & $0.527(+/-0.07)$ & $0.738(+/-0.08)$ \\
\cline { 2 - 4 } & R1-R4 & $0.528(+/-0.07)$ & $0.755(+/-0.08)$ \\
\hline
\end{tabular}

*Numbers are quadratic Kappa values (+/-SD) 
Table 3 Comparison of area under the ROC curve (Az), according to reader experience. Az and standard error (SE) are presented as measures of the discrimination between benign or high-risk and malignant lesions

\begin{tabular}{l|ccccc}
\hline $\mathrm{Az}$ & Overall & $\mathrm{R} 1$ & $\mathrm{R} 2$ & $\mathrm{R} 3$ & $\mathrm{R} 4$ \\
BIRADS $_{\text {MAммо }}$ & $0,692(+/-0.02)$ & $0.741(+/-0.04)$ & $0.711(+/-0.04)$ & $0.651(+/-0.04)$ & $0.665(+/-0.05)$ \\
BIRADS $_{\text {Mаммо+томо }}$ & $0,809(+/-0.02)$ & $0.792(+/-0.04)$ & $0.819(+/-0.03) *$ & $0.806(+/-0.03)$ & $0.822(+/-0.03)$ \\
$P$ & $<0,01$ & 0.07 & 0.01 & $<0.001$ & $<0.001$ \\
\hline
\end{tabular}

* $P$ value corresponds to the difference between Az BIRADS MAmmo $_{\text {and Az BIRADS }}$ MAмmo+томо

Table 4 Differentiation between benign or high risk and malignant lesions

\begin{tabular}{l|cccc|cc|cc|cc|}
\hline & \multicolumn{2}{|c|}{ Mean } & \multicolumn{2}{c|}{ R1 } & \multicolumn{2}{c|}{ R2 } & \multicolumn{2}{c|}{ R3 } & \multicolumn{2}{c|}{ R4 } \\
& M & M+T & M & M+T & M & M+T & M & M+T & M & M+ \\
Sensitivity (\%) & 72,9 & 89,3 & 83.6 & 86.8 & 81.9 & 90.1 & 59 & 86.8 & 67 & 93.4 \\
Specificity (\%) & 50,5 & 50,7 & 50 & 54.2 & 43.6 & 54.8 & 58.5 & 54.2 & 50 & 39.3 \\
PPV (\%) & 48,9 & 53,4 & 52 & 55.2 & 48.5 & 53.9 & 48 & 55.2 & 46.5 & 50 \\
NPV (\%) & 74,2 & 88,2 & 82.4 & 86.4 & 78.8 & 90.4 & 68.7 & 70.1 & 70.1 & 90.2 \\
Accuracy (\%) & 53,9 & 66,7 & 63.2 & 67 & 58.7 & 72.2 & 58.7 & 67 & 56.7 & 60.6 \\
\hline
\end{tabular}

$\mathrm{TP}=$ true positive, $\mathrm{TN}=$ true negative, $\mathrm{FP}=$ false positive, $\mathrm{FN}=$ false negative, $\mathrm{PPV}=$ positive predictive value, NPV $=$ negative predictive value No. $=$ Total number of lesions 
Table 5. Comparison of tomosynthesis according to reader experience

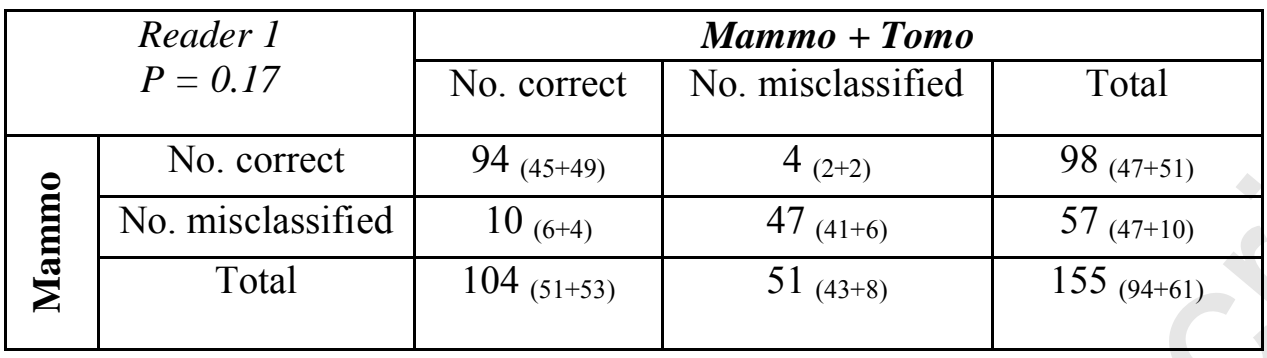

No. $=$ total number of lesions $($ benign + malignant)

\begin{tabular}{|c|c|c|c|c|}
\hline \multicolumn{2}{|c|}{$\begin{array}{l}\text { Reader } 2 \\
P=0.02\end{array}$} & \multicolumn{3}{c|}{ Mammo + Tomo } \\
\cline { 3 - 5 } \multicolumn{2}{|c|}{} & No. correct & No. misclassified & Total \\
\hline \multirow{2}{*}{ 节 } & No. correct & $86_{(39+47)}$ & $5_{(2+3)}$ & $9_{(41+50)}$ \\
\cline { 2 - 5 } & No. misclassified & $16_{(8+8)}$ & $48_{(45+3)}$ & $64_{(53+11)}$ \\
\cline { 2 - 5 } & Total & $102_{(47+55)}$ & $53_{(47+6)}$ & $155_{(94+61)}$ \\
\hline
\end{tabular}

No. $=$ total number of lesions (benign + malignant)

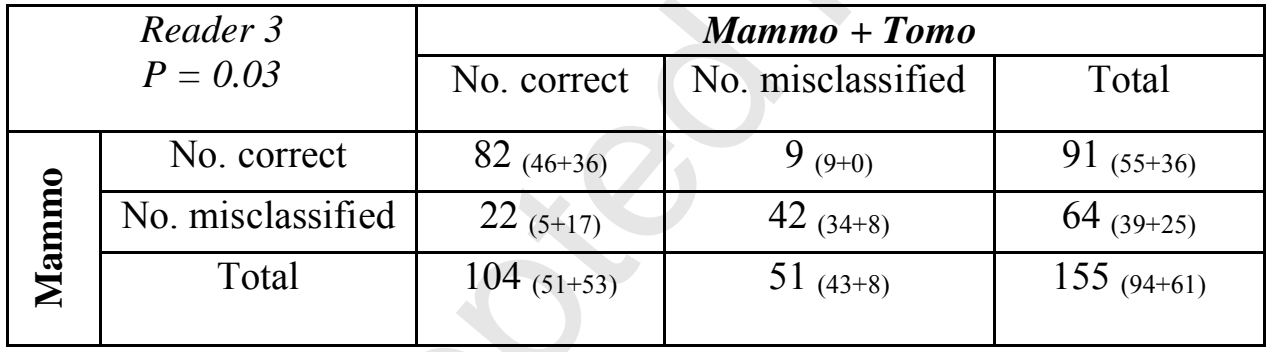

No. $=$ total number of lesions (benign + malignant)

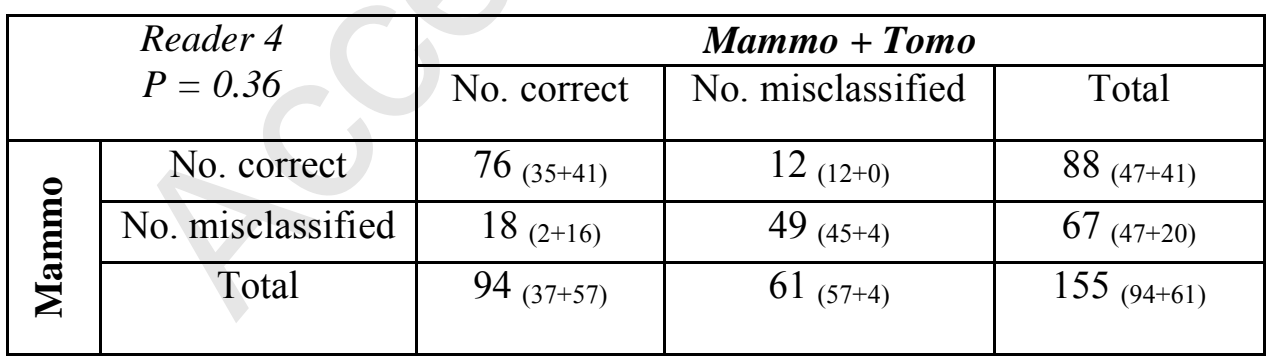




\section{FIGURES}

Fig. 1 Invasive lobular carcinoma in a 55-year-old menopausal woman without any personal or familial history of breast cancer or any palpable mass who was referred for mammographic screening. a, b Digital mammogram suggests the presence of an asymmetric density on the left axillary projection, which is considered as a subtle image. c Breast tomosynthesis unequivocally demonstrates this architectural distortion (arrow).

Fig. 2 Invasive ductal carcinoma in a 52-year-old menopausal woman without any personal or familial history of breast cancer and referred for screening. All readers considered breasts as dense rated type 3. a Digital mammogram suggests the presence of an asymmetric density in the left breast which is considered as a subtle image on oblique view (a and $\mathbf{b}$ ) and as invisible on craniocaudal view (c and d) e Breast tomosynthesis clearly demonstrates an architectural distortion associated with a mass (arrow).

Fig. 3 Invasive Lobular carcinoma in a 54 year-old menopausal woman with a familial history of breast cancer without any palpable mass addressed for screening. Breasts were considered dense, rated as type 3 by all readers. All readers missed the cancer reading digital mammography (BI-RADS 2) (a, b, c, d) but reclassified as BIRADS 5 breast imaging using breast tomosynthesis (arrow) (e and additional material fileVideo corresponding to figure 3e)

Fig 4 : Comparison of the performance difference according to reader experience 


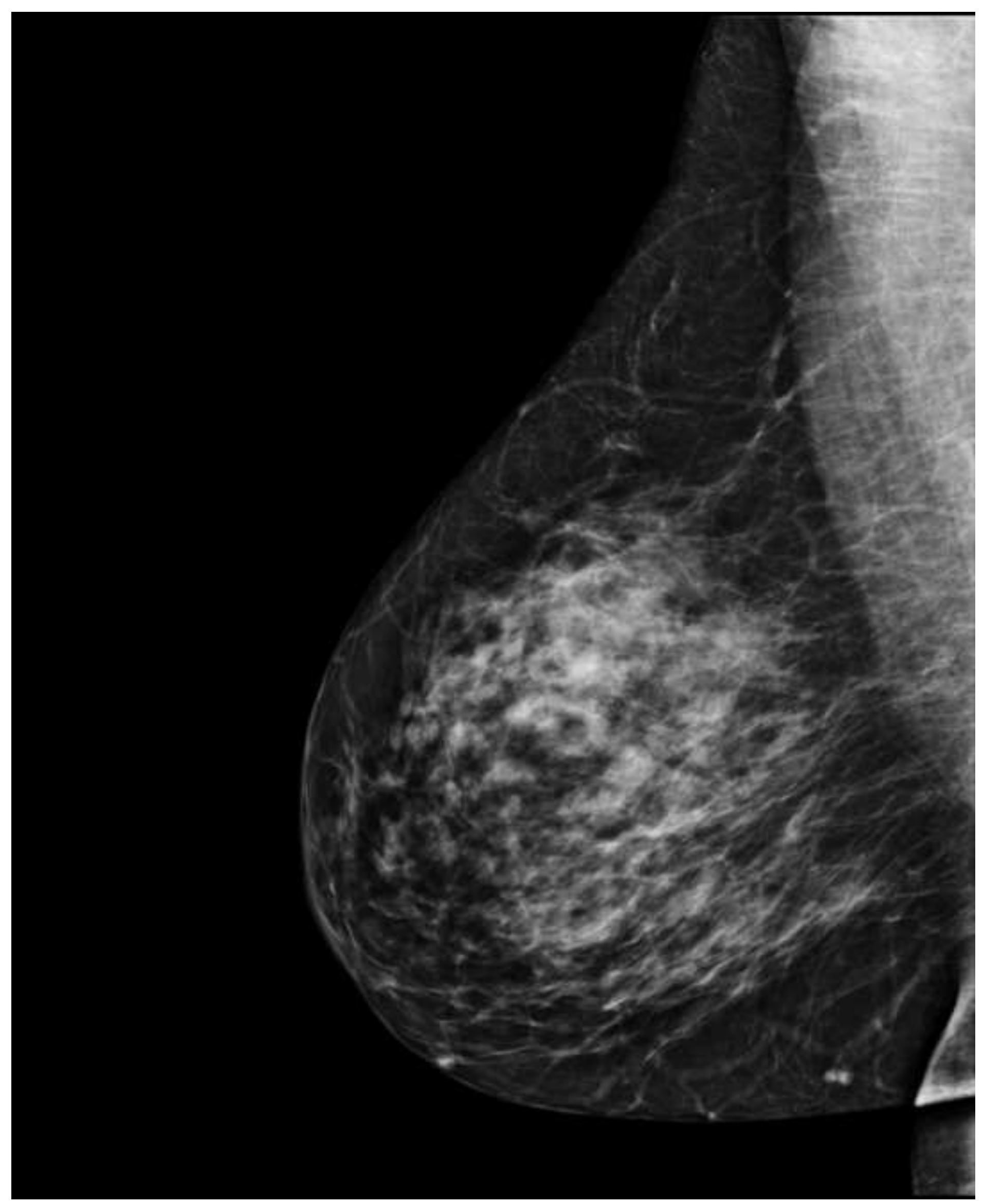

Page 25 of 38 


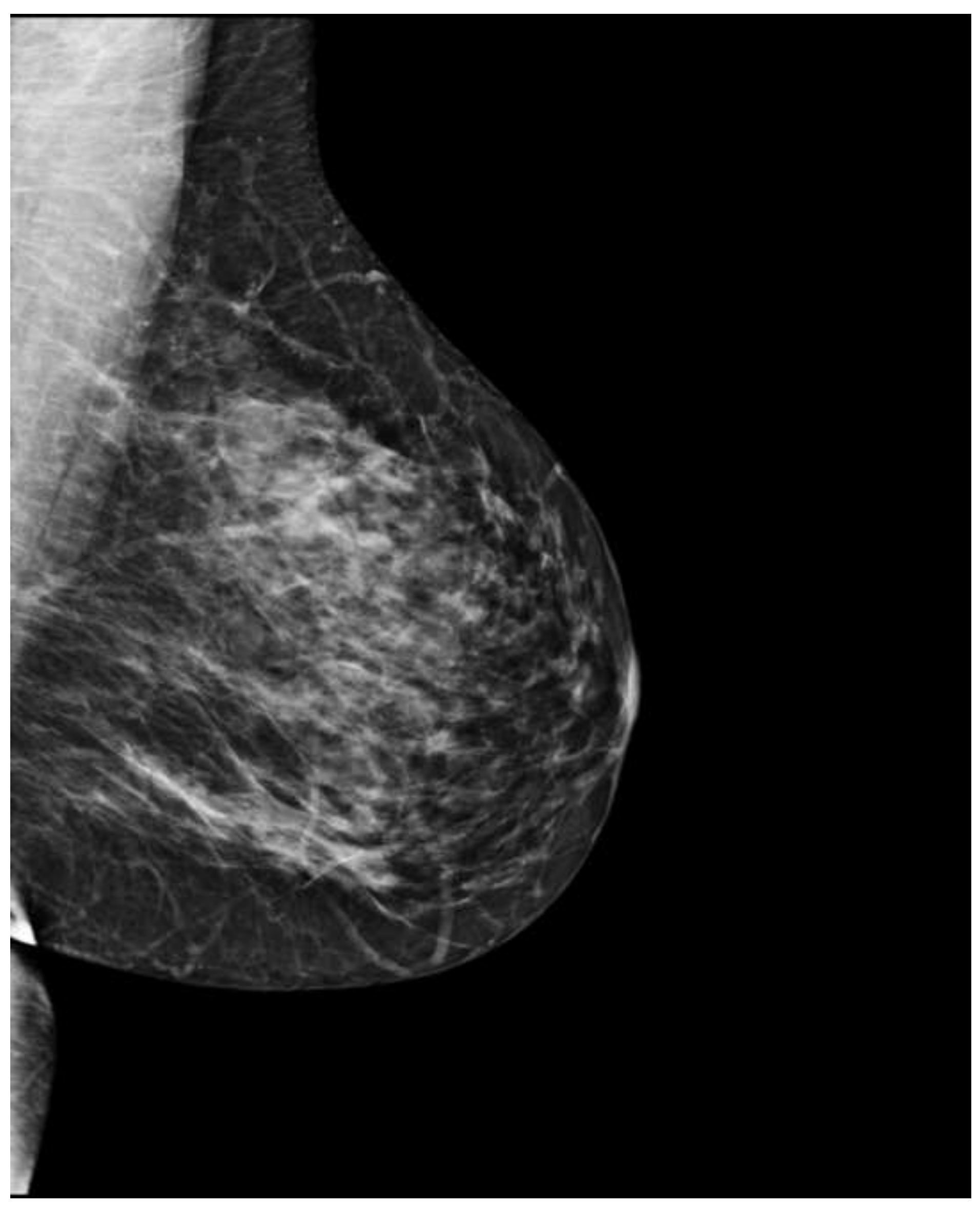

Page 26 of 38 


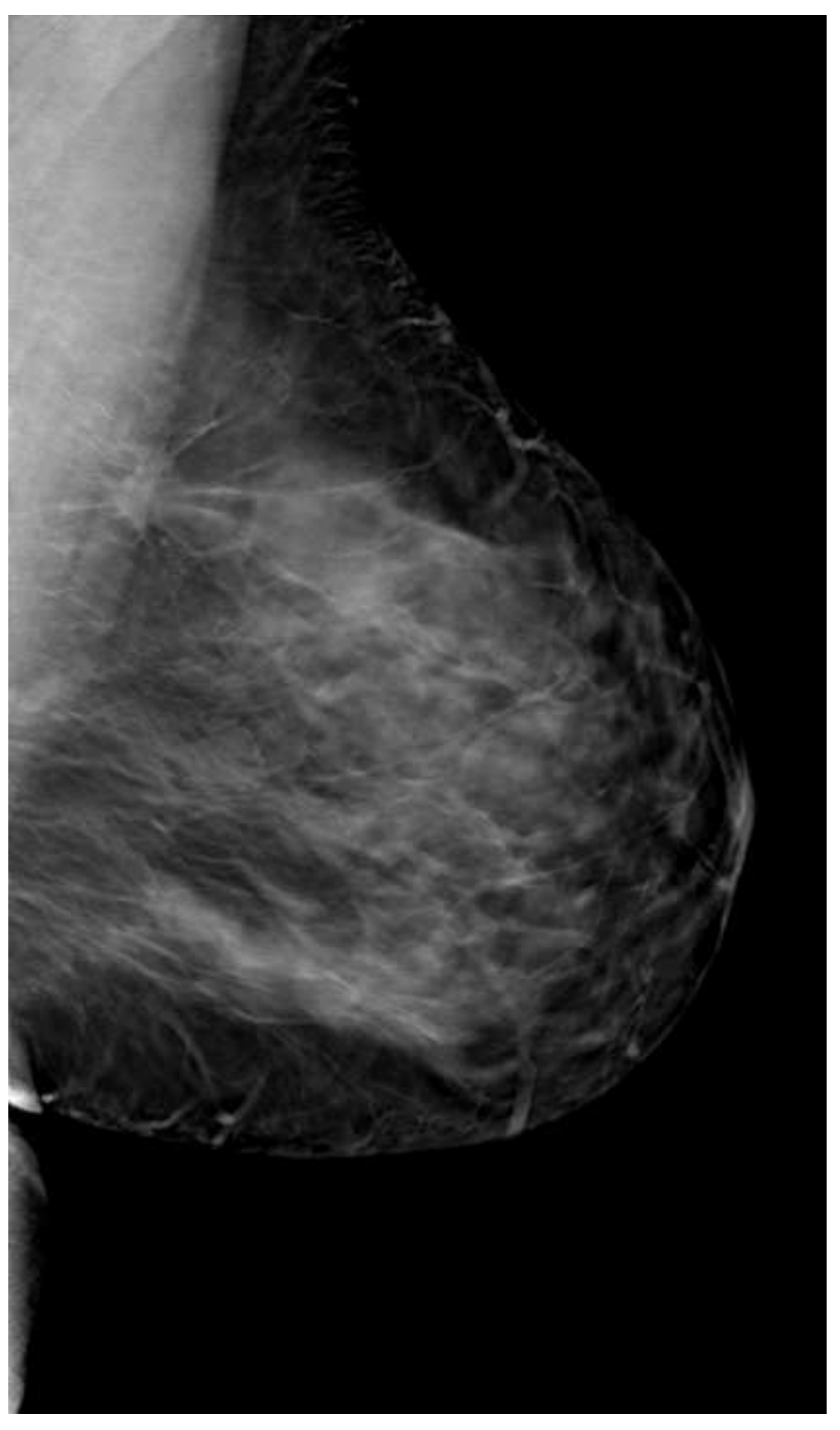

Page 27 of 38

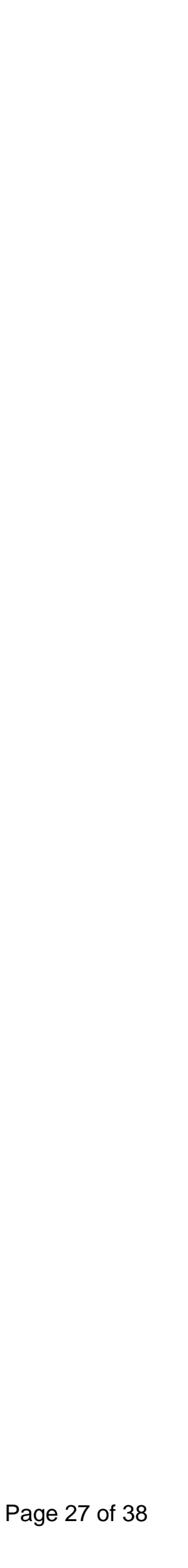

(2)




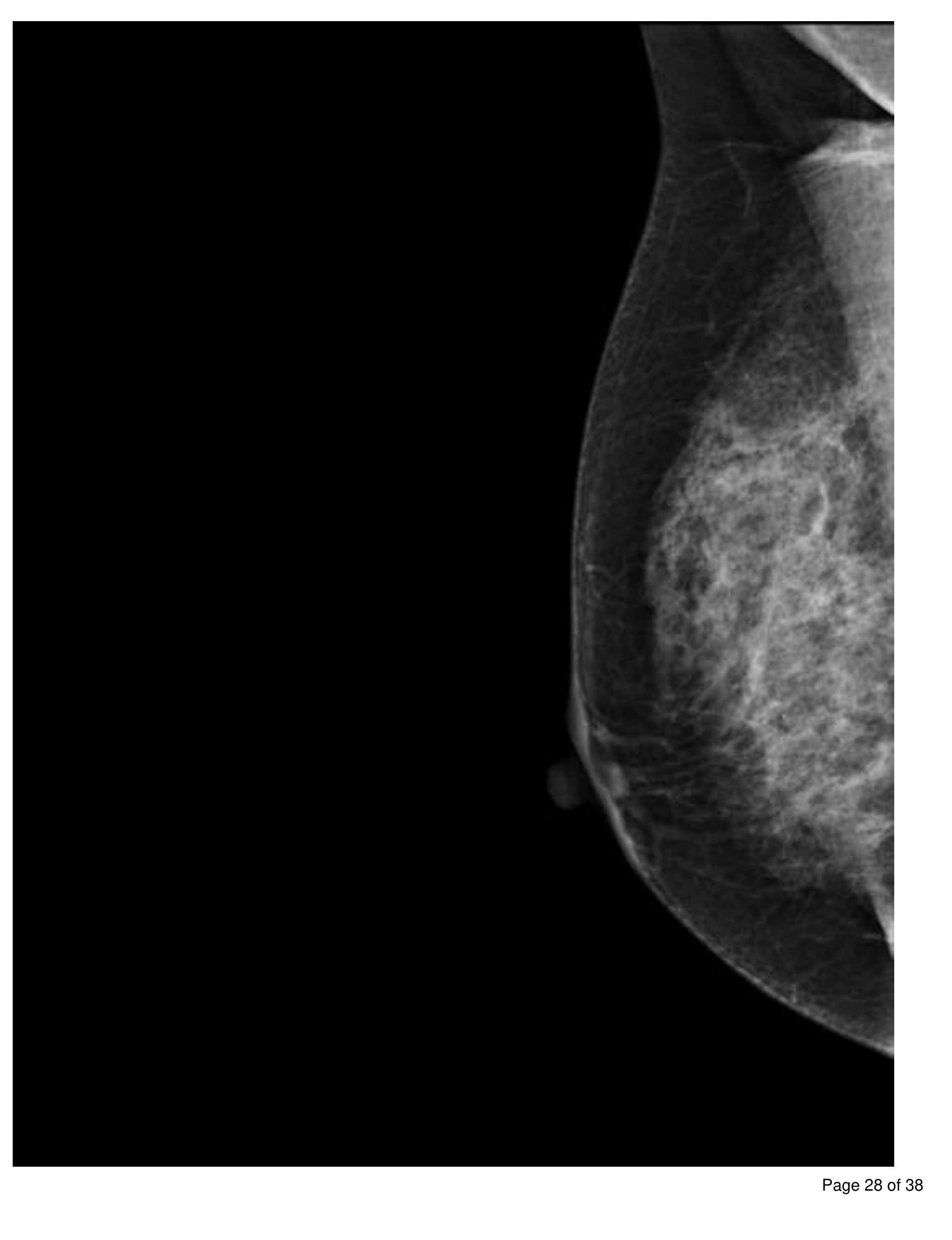

Page 28 of 38

\author{
age 28 of 38
}




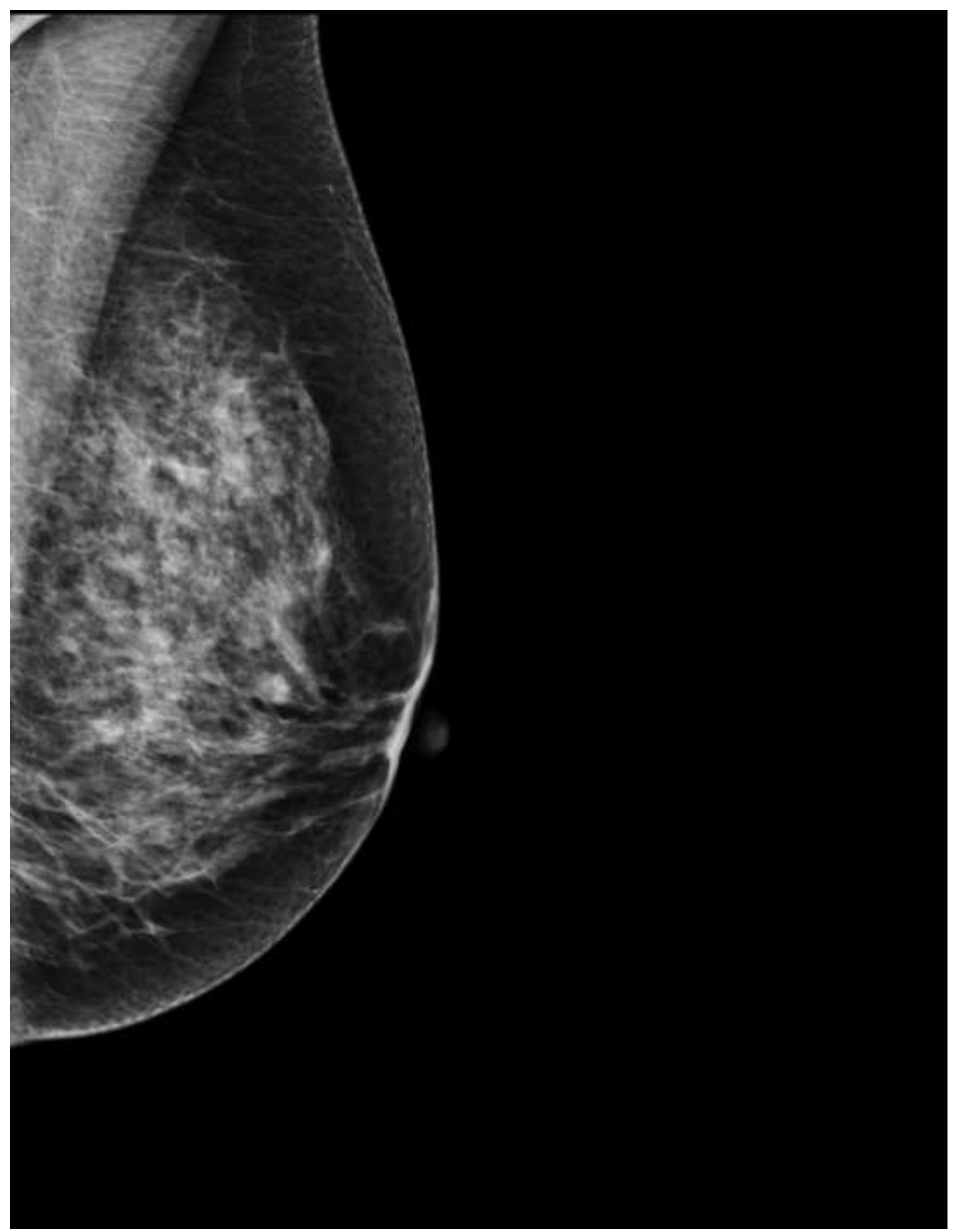

Page 29 of 38

TED MANUSCAIPT 


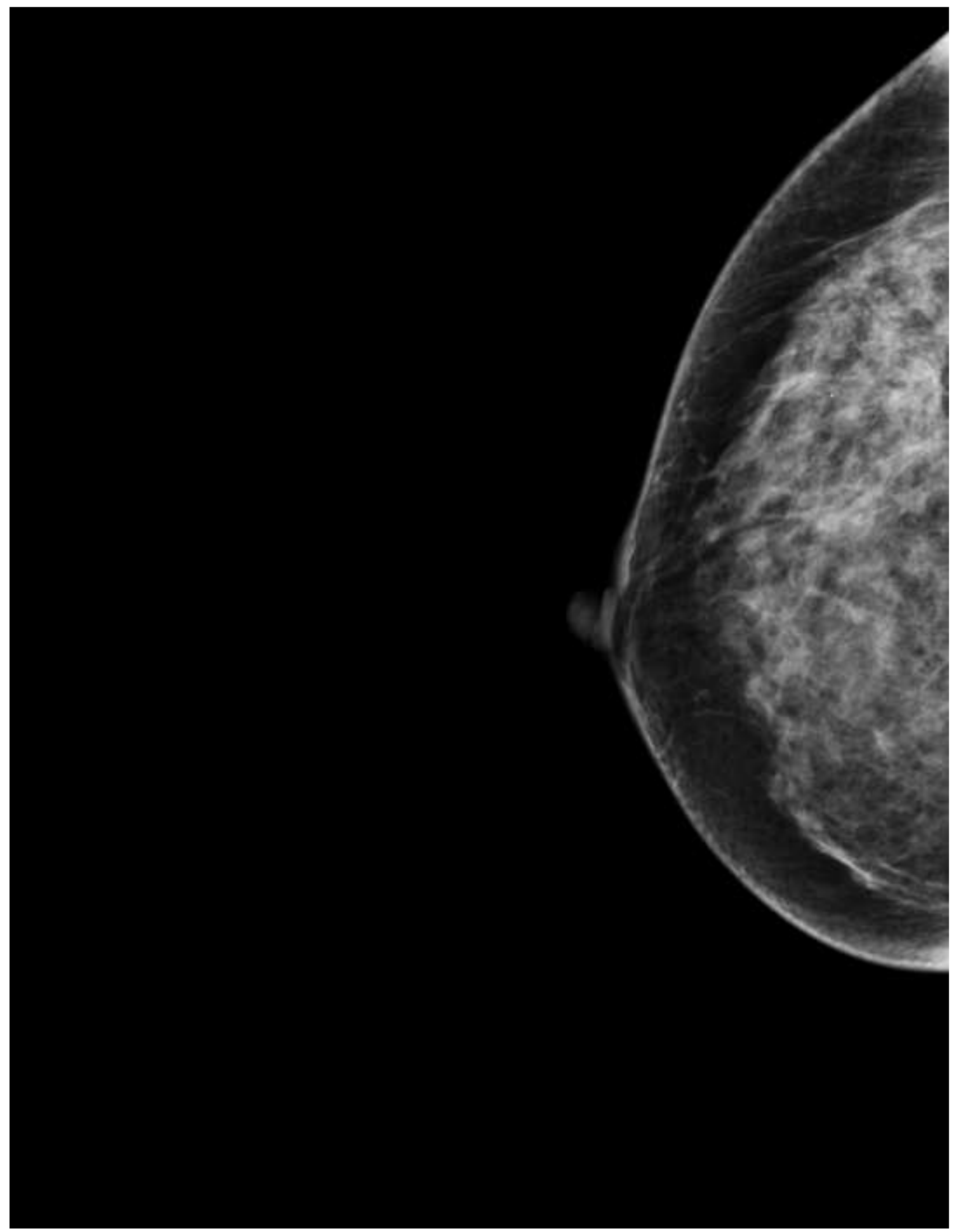

Page 30 of 38 


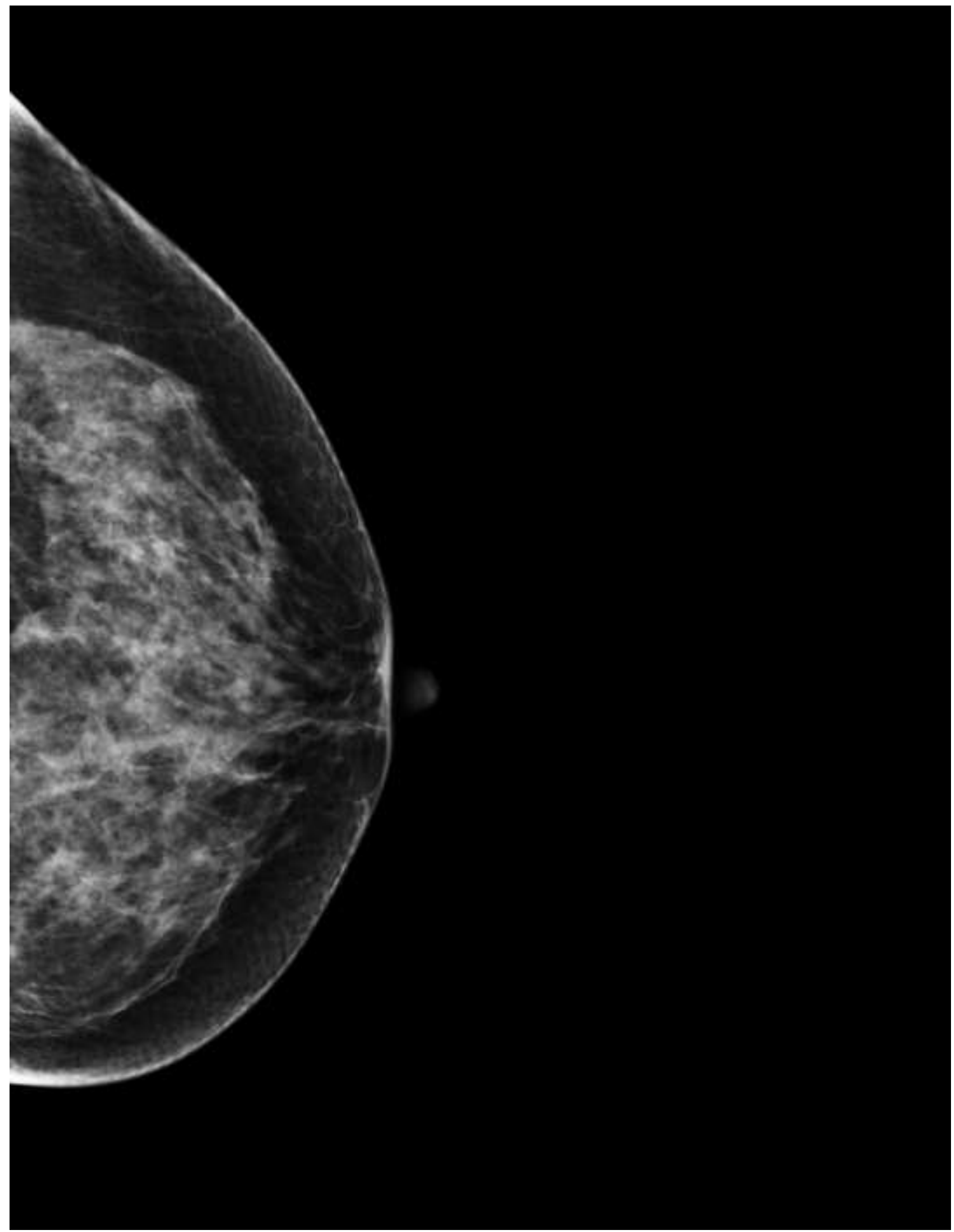

Page 31 of 38 


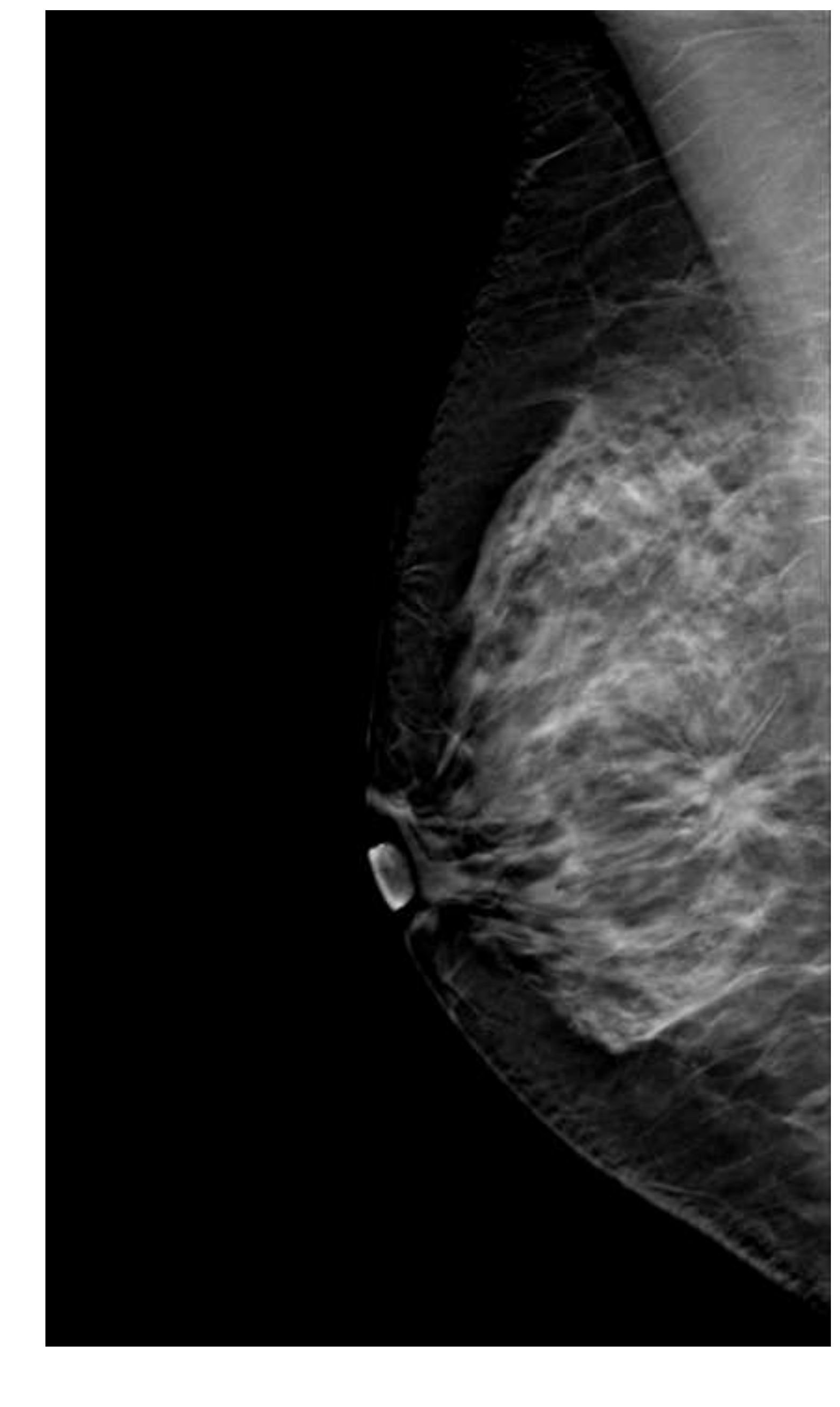

ge 32 of 38

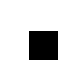

\section{Page 32 of 38}

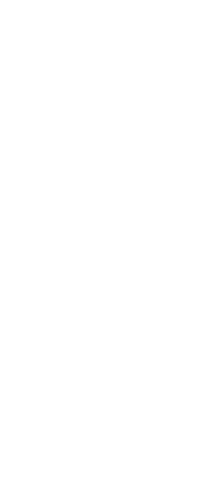




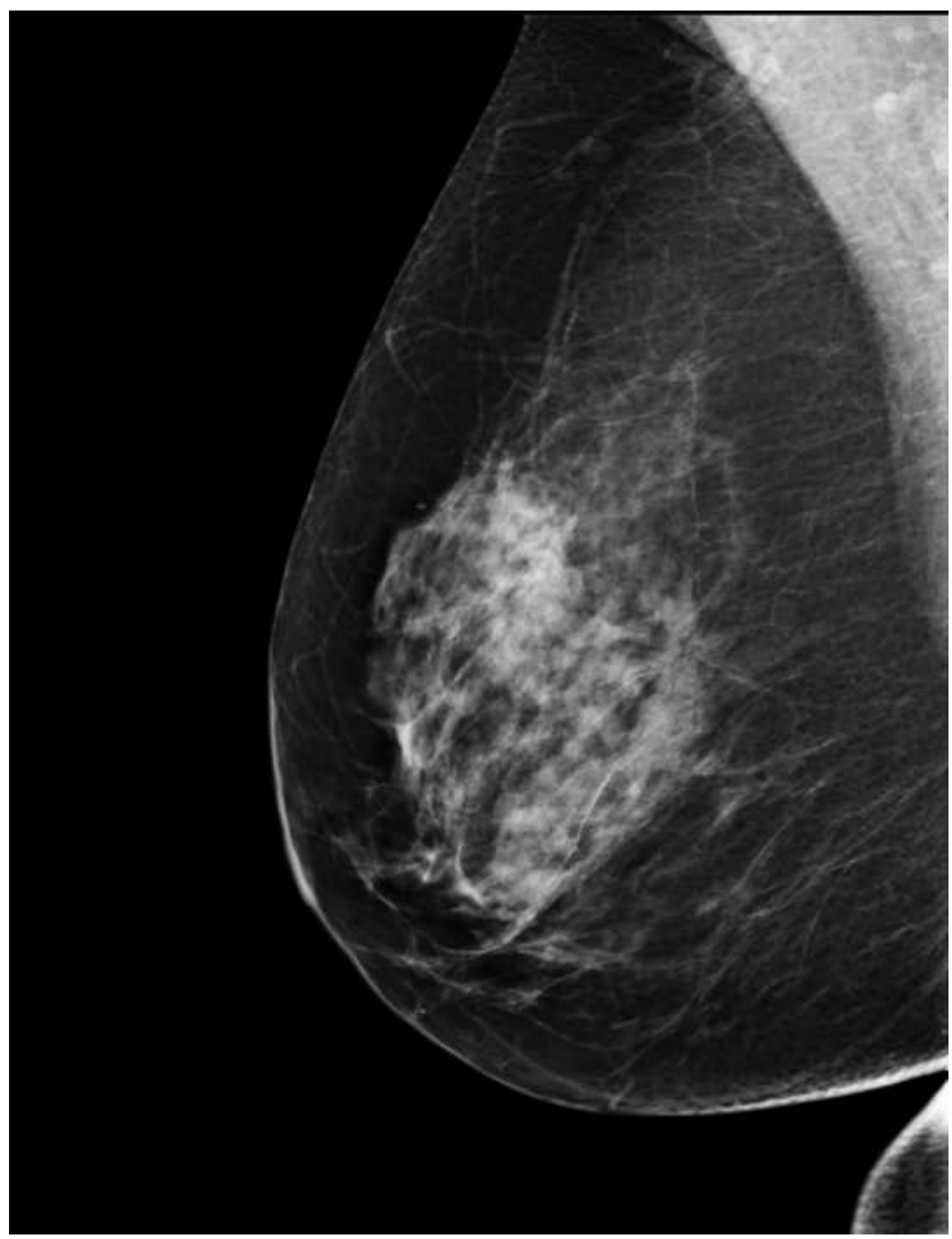

Page 33 of 38 \\ ACCEPTED MANUSCRIPT}




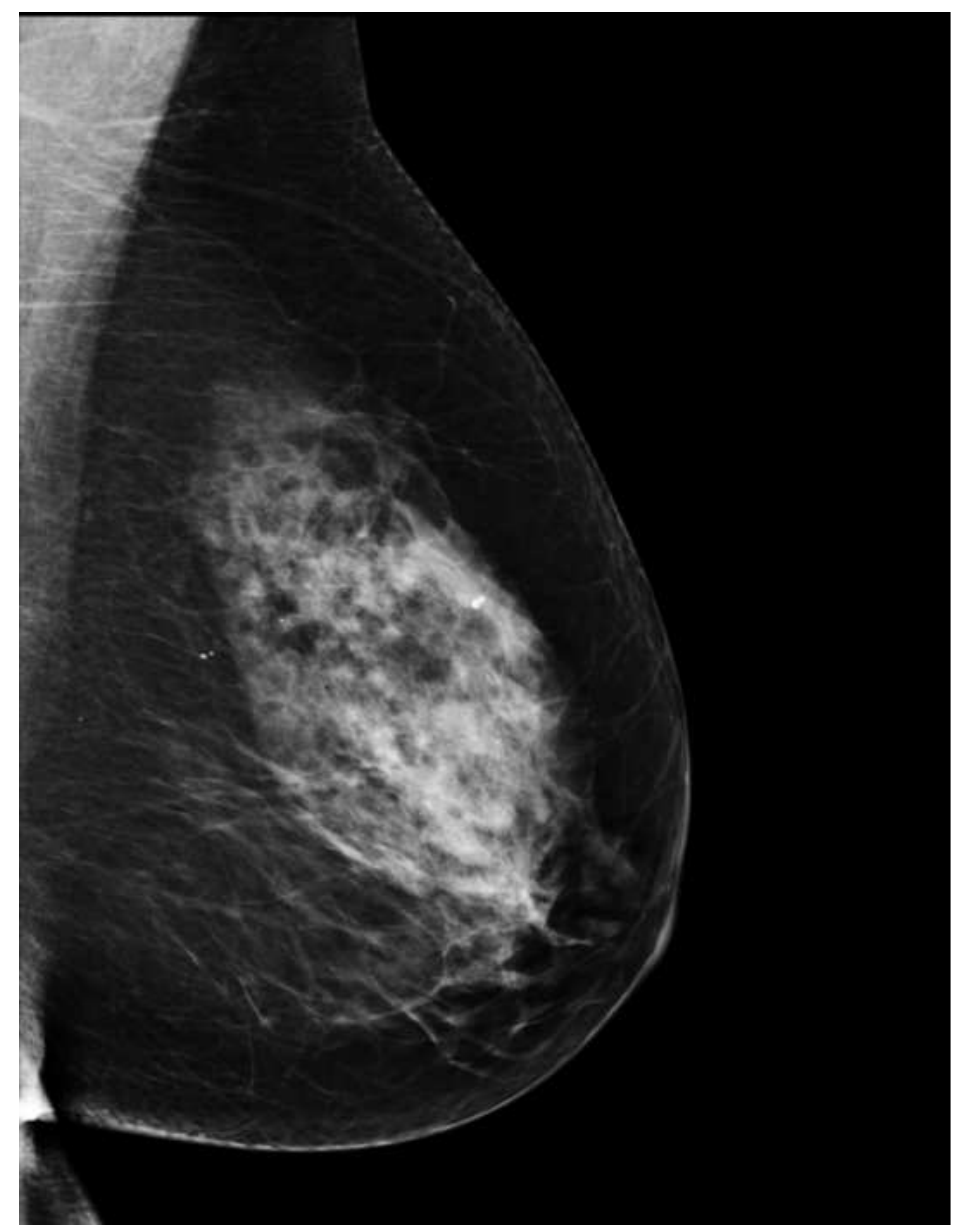
(x)

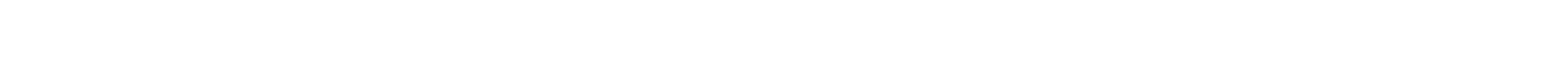




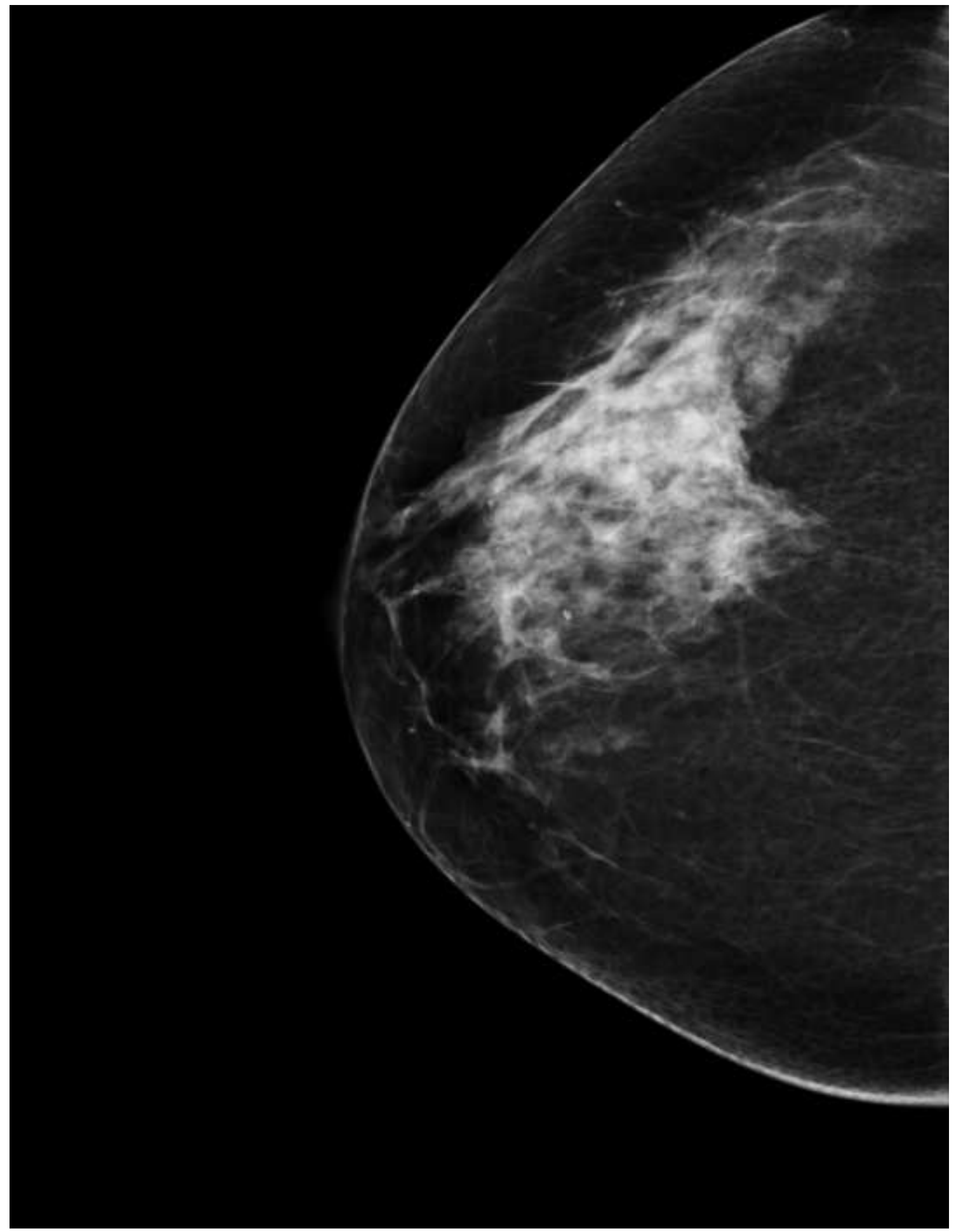

Page 35 of 38 

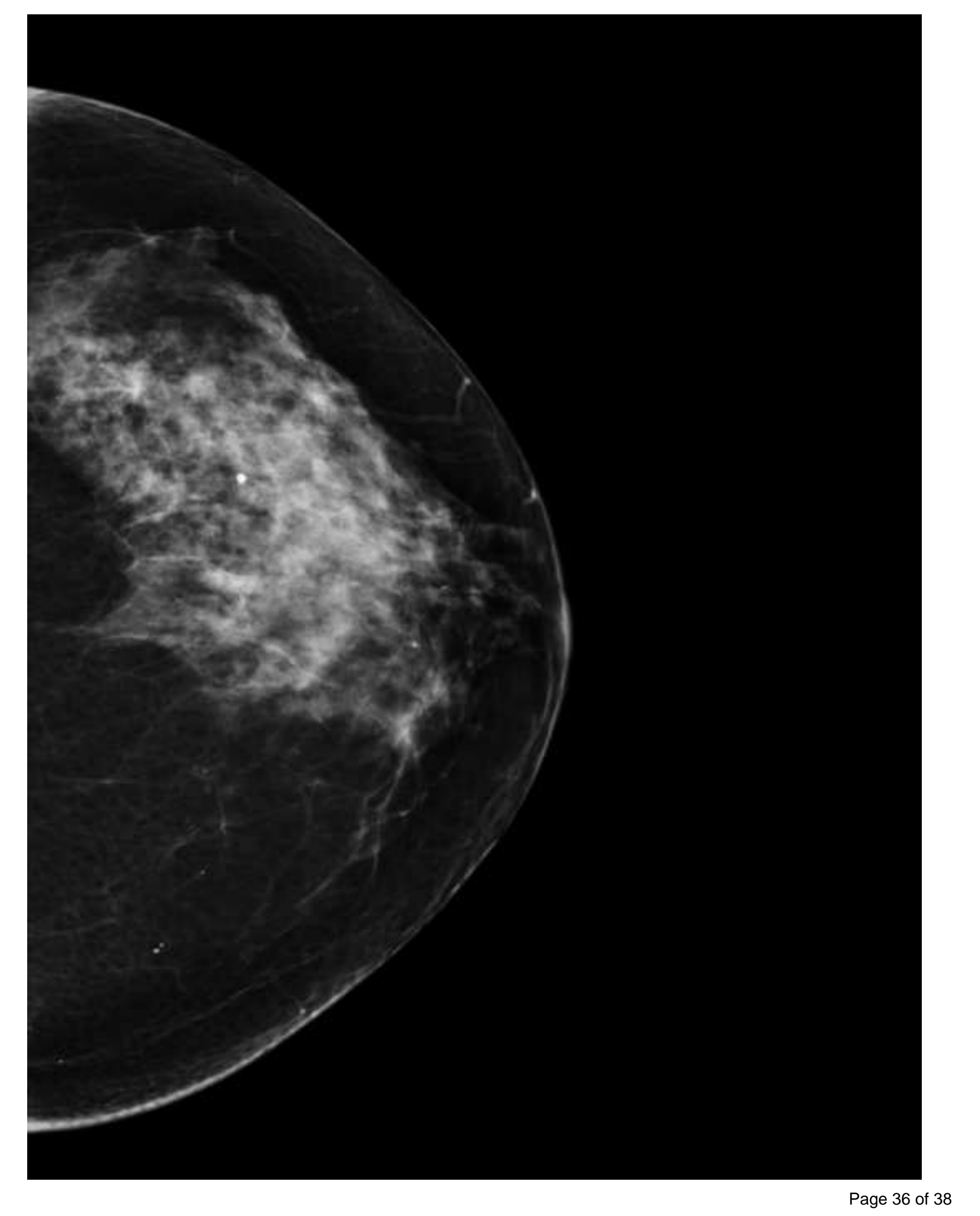


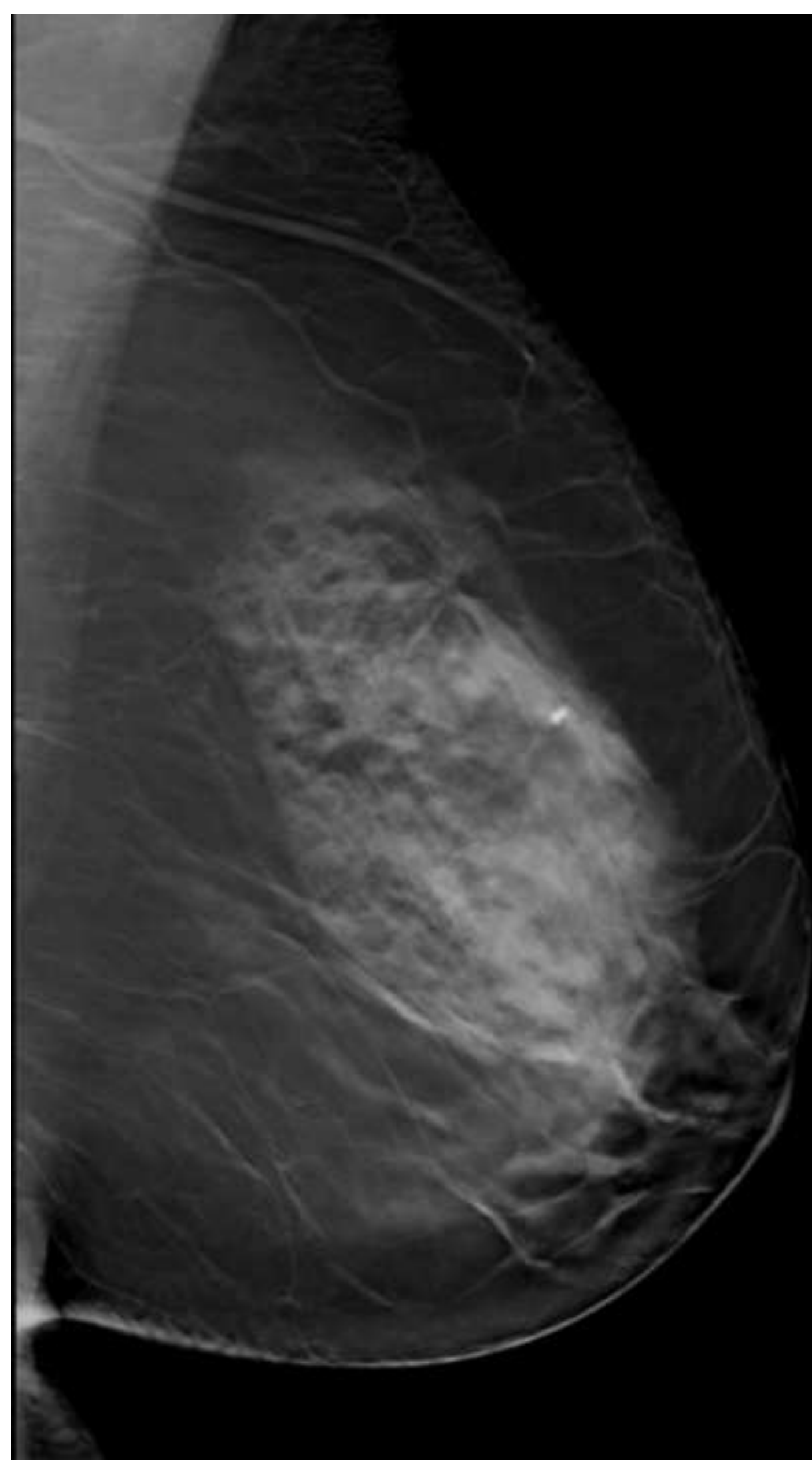

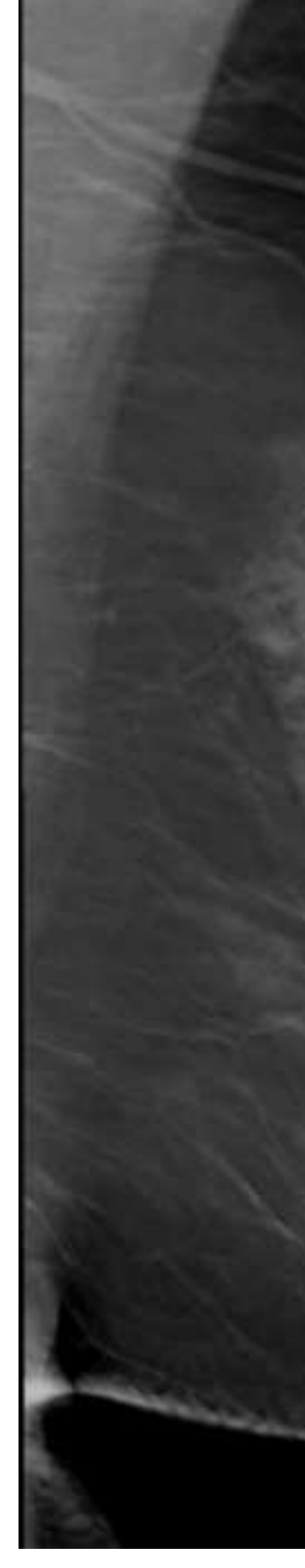

-

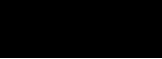


Comparison of the perfomance difference according to reader experience

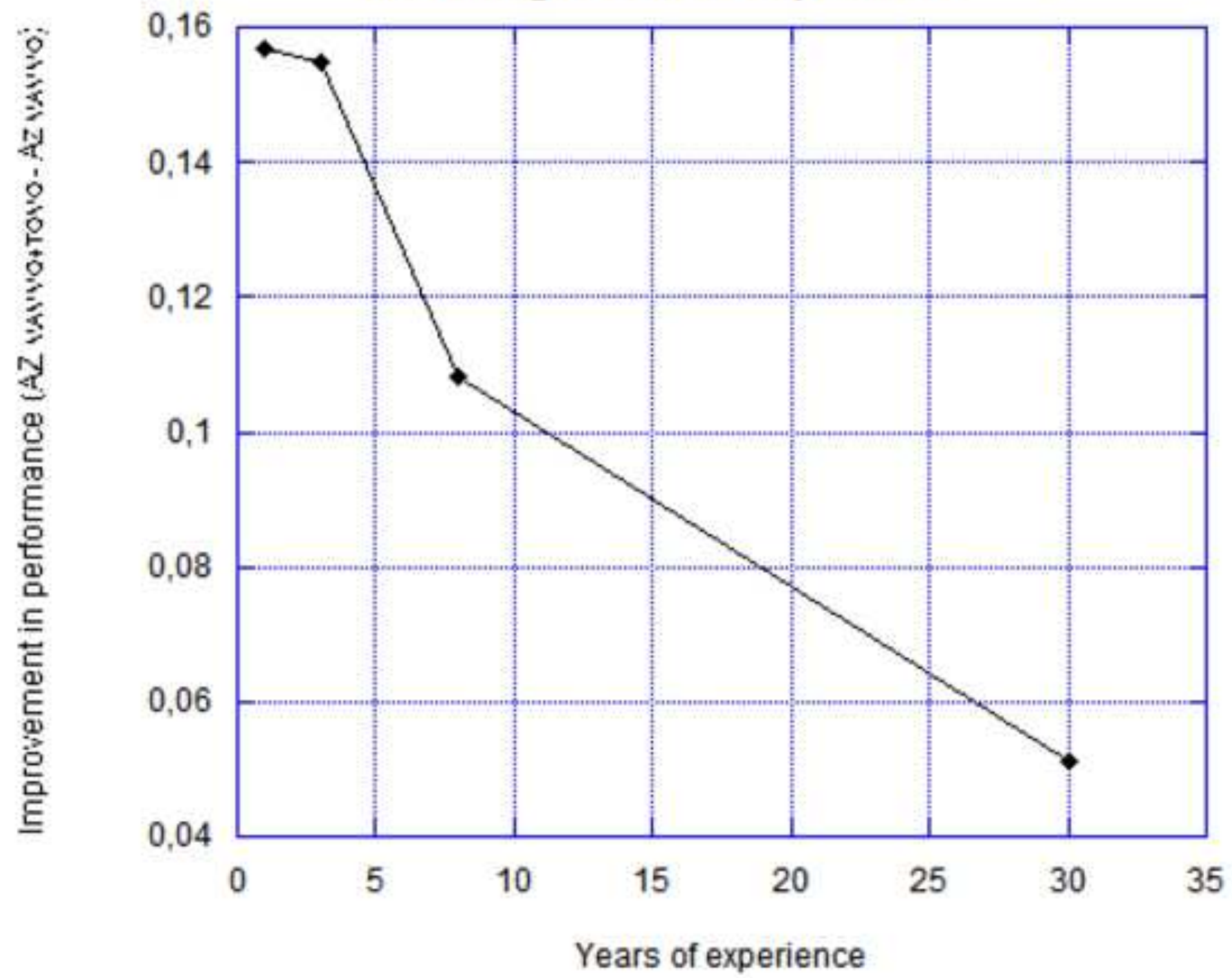

rage 38 or з 38 